\title{
A Pragmatic Study of Ambiguity and Puns in English Humor
}

\author{
Gao Chao ${ }^{1, a}$ Ren Xinghua ${ }^{2, b}$
}

1 Shandong Women's University, University technology park, Chang qing, Jinan, Shandong, China 2 Shandong Experimental High School, No.7 Jing Qi road, Shizhong, Jinan, Shandong, China a iamgaochao@126.com, b rrenxinghua@126.com

Keywords: Humor, ambiguity, pun, Cooperative Principles, Relevance theory

\begin{abstract}
Humorous language, as the main form to express humor, is popular in our life. In humorous language, ambiguity and puns are important devices to create humor. They also play active roles in helping people to achieve positive communication effects, which make them have distinctive pragmatic characteristics.

This paper analyzes the pragmatic characteristics of ambiguity and puns in English humor. First, it introduces the definition and classification of ambiguity and puns, then thoroughly studies the pragmatic features reflected in English humor such as the Deixis, the Presupposition, the Cooperative Principle and the Relevance theory.
\end{abstract}

\section{Introduction}

Ambiguity is a common phenomenon that cannot be avoidable in any natural language. Usually it is defined as expressions which have more than one meaning. Ambiguity plays both negative and positive roles. Negative ambiguity will be an obstacle to communication so it should be avoided, while intentional ambiguity can create a special effect such as irony, sarcasm, humor, etc. Ambiguity can be divided into three types. They are phonic ambiguity, lexical ambiguity, and syntactic ambiguity.

Pun is a figure of speech depending upon a similarity of sound and a disparity of sound and a disparity of meaning. The flexible use of puns can refresh the language and achieve euphemism and humor. Puns can be regarded as a special form of ambiguity. Therefore it can also be divided into three types. They are phonic puns, lexical puns, and syntactic puns.

As ambiguity and puns have these functions, they are the important basis and features in English humor. This paper is a tentative endeavor to analyze ambiguity and puns in English humor from the pragmatic view. Appropriate use of ambiguity and puns can enrich language and make language more vivid and appealing.

\section{Pragmatic Features and Humor analysis}

\subsection{Deixis}

Elements of language that are so contextually bound are called deixis. It used not only special words such as this, that, here, there, I, you, he, she, etc. but also common words and grammar such as noun phrase, tense and voice of verbs, etc. Most important of all, the meaning of deixis depends on the context. Thus the unclear context may lead to ambiguity in deixis, which can create humor. For example:

[1] Nurse: "Now let's take off our clothes, and see how much we weigh."

Little boy:” You go ahead, I don't want to.”

In this conversation, the nurse used the deixis "let's, our, we" in order to get closer to this boy and made him feel intimate and comfortable. However, the boy did not understand its pragmatical meaning and gave a funny response.

\subsection{Presupposition}

Presupposition is defined in terms of assumptions the speaker makes about what the listener is likely to accept without challenge. According to Stalnake, “presuppositions are what are taken by the 
speaker to be the common ground of the participants in the conversation.” Presupposition is very important to successful communication. Both of the communicators should share certain knowledge, or their communication will not continue. For example:

[2] A nine-year-old boy stood in the entrance to the shoe repair shop watching the man at work.

"What do you repair boots with, mister?" he suddenly asked.

"Hide," replied the shop repairer sharply.

“E-r-r-,eh?” asked the boy.

"I said hide," replied the shoe repairer impatiently.

"What for?" the boy insisted, somewhat surprised.

"Hide! The cow’s outside," said the shoe repairer.

"I don't care if it is. Who's afraid of a cow, anyway?" said the youngster loudly.

This conversation mentioned "hide" many times. Therefore each side should know the meaning of "hide" which is the presupposition of this conversation. However, the boy only knew one of the meanings as "to conceal", while the man referred its second meaning as "the cow skin". That's the ambiguity which leads to the humor.

\section{Pragmatic Theories and Humor analysis 3.1 Cooperative Principle}

Why don't people say what they mean but prefer to express their meaning in a roundabout way? The answer lies in the way people communicate with each other. It is assumed that speakers and hearers involved in conversation are generally cooperating with each other. The American philosopher H. Paul Grice believes that to conduct successful and happy interaction, people are actually observing a certain cooperative principle. The principle that he introduces has the general name of Cooperative Principle. Within this principle, Grice suggest four maxims:

(1) The Maxim of Quantity

a) Make your contribution as informative as is required for the current purpose of the exchange

b) Do not make your contribution more informative than is required

(2) The Maxim of Quality

a) Do not say what you believe to be false

b) Do not say that for which you lack adequate evidence

(3) The Maxim of Relevance

Make your contribution relevant to communication

(4) The Maxim of Manner

Be perspicuous, and specifically
a) Avoid obscurity
b) Avoid ambiguity
c) Be brief
d) Be orderly

\subsubsection{Violating of Quantity Maxim}

[3] Student: I et seven biscuits for breakfast.

Teacher: Ate.

Student: Well, maybe it was eight.

In the student's utterance, he makes a mistake and pronounces 'ate' as 'et'. It is a lexical ambiguity. If the teacher corrects the student's mistake by saying "You should say 'I ate seven biscuit for breakfast'", then there will be nothing funny. Yet the information the teacher gives is too little for the student as he doesn't realize his mistake at all, so he mistakenly takes it as 'eight'. It is so vivid and we seem to see a careless kid and a helpless teacher.

\subsubsection{Violating of Quality Maxim}

[4] "I get a warm reception wherever I go" 
"You must be very popular."

"No, I’m a fireman."

In this example, "warm" is an ambiguity word. It can have two explanations. One is "a comfortable degree of hot", and the other is "friendly and responsive". The speaker compares "fire" to "warm reception", which violate the maxim of Quality for not speaking sincerely. That's why the hearer misunderstands it. But then the speaker makes it clear and shows his sense of humor.

\subsubsection{Violating of Relevant Maxim}

[5] Diner: Waiter, I am in a hurry. Will the cakes be long?

Waiter: No, sir, they will be round.

In this example, "long" is an ambiguity word. It can have two explanations. One is the opposite of "round" in shape and the other is the opposite of "short" in length. We are not necessarily to say that the waiter violates the maxim of relevance. In fact, if we only have the question "will the cakes be long?" and no contextual information is given, it is natural for the waiter to answer in such a way. The reason is due to the polysemy of "long". Since we have the context as "I am in a hurry", the waiter must be consciously answering this question in a humorous way.

\subsubsection{Violating of Manner Maxim}

[6]One high-ranking official once responded to a subordinate's request for a raise by saying: "Because of the fluctuational predisposition of your position's productive capacity as juxtaposed to government standards, it would be momentarily injudicious to advocate an increment.” The staff person said, "I do not get it.” The official responded, "That is right."

In this conversation, the official uses a series of formal and complex words, which are difficulty to understand at once. The stylistics of these sentences obviously is unsuitable for this occasion. Therefore, he violates the Maxim of Manner. Furthermore, he skillfully uses the double meanings of the sentence "I don't get it" (a syntactic pun) to refuse the staff person's request in a humorous way.

\subsection{Relevance theory}

Relevance theory was first proposed by Sperber and Wilson in a book entitled "Relevance: Communication and Cognition" (1986). They believe that communication is a process involving two information-processing devices. One device modifies the physical environment of the other. As a result, the second device constructs representation similar to representations already stored in the first device.

\subsubsection{Flouting of Relevance theory}

According to the Relevance Theory, the speaker always tries to convey something clearly in the utterance to the hearer. The sentence might mean different things in different contexts. But what the speaker really is only one of them. So the hear should study the relevance between the utterance and the context. However, sometimes the hearer may misinterpret the real meaning intentionally or unintentionally, that is the flouting of the Relevance Theory. For example:

[7] Judge: “Order! Order! Order in the court! ”

Prisoner: "I'll take a ham sandwich on rye with beer."

Here is a lexical ambiguity. "Order" has two explanations. One is a command and the other is a requirement for food. Based on the context of the example, it doesn't take long for us to make sure what information the Judge wants to transfer. However, the prisoner is designed to misinterpret the meaning and therefore the conversation is endowed with great humor.

\subsection{Puns and context selection}

The advantage of puns lies in their potential multiplicity of meanings. In other words, thanks to their multiple contexts, puns are superior to plain statements. In this case, a special context selection is necessary and significant.

This context selection will finally influence the process of interpreting puns. Based on Relevance Theory, a pun functions as follows: two or more interpretations are intentionally triggered by the communicator of a pun, but the addressee rejects the most accessible interpretations in search of more acceptable interpretation. Thus the essence of the pun lies in its access to multiple interpretations. For a pun to be successful it is necessary that the addressee should access more than one interpretation of a given utterance based on a special context selection. For example: 
[8] A: Why are lawyers all uneasy sleepers?

B: Because they lie first on one side, and then on the other, and remain wide awake all the time

Here "lie" is a pun, it can be interpreted differently in the different context, one refers to the sleeping state, and the other refers to the engagement of lawsuit. In the former context, "lie" means a position; while in the latter it means to tell a lie. In this dialogue, speaker B exposes the nature of lawyer in an ironic and humorous way.

\section{Summary}

No matter how the society develops, humor will never be out of our life. As a matter of fact, more and more people have realized the power of humor and prefer to be humorous. To be a humorous person, we should not only learn how to create personal humor but also learn how to appreciate or interpret humor. As English majors, we should not only learn how to understand English humor but also to view it from the theoretical point of view. Humorous language, as a main component of humor, is often in the form of conversations. That is to say humor can be studied from the pragmatic view.

To sum up, the author tends to find out how humorous effects are achieved by ambiguity and puns from the pragmatic view. This kind of analysis not only reinforces the functions of ambiguity and puns but also demonstrates the common strategies used to create humor.

\section{References}

[1] Leech, G. Principles of Pragmatics. London: Longman (1983).

[2] Levinson, Stephen C. Pragmatics. Cambridge University Press. (1983).

[3] Sperber, Dan \& Deirdre Wilson. Relevance: Communication and Cognition. UK: Basil Blackwell. (1986). 